\title{
Por um ensino de História referenciado na Educação Popular
}

For a History teaching based on Popular Education

\author{
Israel Soares de Sousa* \\ Severino Bezerra da Silva ${ }^{* *}$
}

\section{Resumo}

Buscamos refletir sobre a prática do ensino de História no Brasil e suas características eurocêntricas, na tentativa de superação do ensino tradicional e conteudista. Intentamos também analisar a relação entre a perspectiva da história local e o paradigma da Educação Popular. Essa expectativa parte de nossas vivências profissionais, nas quais percebemos que o ensino de história ainda privilegia os grandes fatos e os heróis, deixando de lado a vivência das classes populares. Nesse sentido, o presente artigo se configura como as reflexões teóricas iniciais do nosso doutoramento em educação, que tem como viés metodológico a Pesquisa Participante, a partir da implementação de um projeto didático em História Local e Educação Popular na Escola Estadual Papa Paulo VI, localizada do Bairro de Cruz das Armas, no município de João Pessoa (PB). Palavras-chave: ensino de História; Educação Popular; história local.

\section{Abstract}

We seek to reflect on the teaching practice of History in Brazil and its Eurocentric characteristics, in an attempt to overcome a traditional teaching based exclusively on contents. We also intent to analyze the possible relationship between the local history perspective and the Popular Education paradigm. This expectancy rises from our professional experience, through which we noticed that the teaching of History, in many cases, still privileges the great facts and heroes, the great men, leaving the poor classes experiences aside. In this sense, the present article encompasses the initial theoretical reflections of our doctorate in Education, whose methodological bias is the Participant Research, from the implementation of a didactic project on Local History and Popular Education at Escola Estadual Papa Paulo VI, located in Cruz das Armas, a neighbourhood in João Pessoa, capital city of Paraíba.

Keywords: History teaching; Popular Education; local history.

\footnotetext{
* Doutor em Educação (UFPB). Professor da Educação Básica na Rede Pública na Paraíba. Membro do Grupo de estudo e pesquisa Observatório da Educação Popular (PPGE-CNPq). João Pessoa, PB, Brasil. israelhistoria@gmail.com

** Doutor em Ciências Sociais - Sociologia (PUC-SP). Professor da Graduação e Pós-Graduação em Educação na Universidade Federal da Paraíba (UFPB). Membro do Grupo de estudo e pesquisa Observatório da Educação Popular (PPGE-CNPq). João Pessoa, PB, Brasil. severinobsilva@uol.com.br
} 
Nosso projeto, referente a História Local e Educação Popular na Escola Estadual Papa Paulo VI, localizada do Bairro de Cruz das Armas, município de João Pessoa (PB), parte do protagonismo dos alunos do Ensino Médio da escola em questão, espaço no qual atuamos como professor de História. Ao final do processo de pesquisa, esperamos ter vivenciado uma prática de ensino de história mais democrática e significativa aos educandos, que vêm produzindo um ebook sobre a história do seu próprio bairro, o que se faz a partir da relação com os conteúdos propostos de história. Na tese em desenvolvimento, intitulada Educação Popular e Ensino de História Local: cruzando conceitos e práticas, esperamos contribuir com a análise da relação entre história local e Educação Popular, compreendendo essa relação como uma prática pedagógica de educação cidadã e crítica, voltada para emancipação dos alunos, considerando-os sujeitos históricos.

O projeto baseia-se em nossa vivência como professor de história na rede pública e privada no município de João Pessoa e na Universidade Federal da Paraíba, trabalhando com a formação do professor/educador nas licenciaturas em Histórias e Pedagogia. Observamos, por meio dessas várias experiências, que ainda se privilegia uma parcela de supostos heróis e de homens considerados importantes no campo político, em detrimento da participação das classes populares nas decisões que refletem nos percursos da história da nação, contexto que nos motiva na pesquisa de doutorado acerca de um ensino de história que seja mais democrático e significativo para os alunos do Ensino Médio.

São comuns nos livros didáticos referências e imagens que evidenciam os atos e feitos de reis, presidentes e líderes totalitaristas, mas que pouco tratam - ou representam de forma negativa - os movimentos sociais e as pessoas consideradas "comuns" pelas esferas política e econômica. Partimos do pressuposto que a história, assim como as outras disciplinas componentes de uma estrutura curricular/escolar, é intencionalmente organizada para a "preparação do cidadão" que se pretende forjar, de acordo com o tipo de sociedade.

Compreendemos que essa função reguladora e normativa, tão presente na disciplina de história, tem sido inserida em uma educação elitista e verbalista, centralizada na figura do professor. A atividade escolar está pautada em aulas nas quais os alunos escutam e tomam notas, preparando-se para exames - com provas orais ou escritas - que têm como finalidade medir a quantidade 
de informações retidas pelos alunos. Por mais que essa realidade nos pareça atual, ela é histórica em nosso país e já era denunciada por Anísio Teixeira em 1957, na primeira edição da sua obra Educação não é privilégio. De acordo com o autor,

História, Geografia e as próprias ciências físicas e naturais também são ensinadas por exposição oral com particular ênfase nos conhecimentos informativos ou na terminologia científica. Nem a função, nem a aplicação do conhecimento têm aí o menor sentido. O conhecimento é algo de absoluto em si mesmo, a ser ensinado para ser repetido nas ocasiões determinadas pelos exames. (Teixeira, 2007, p.51)

Em nosso entender, a configuração educacional que ainda persiste é de uma escola com raízes no medievo, que entende que o conhecimento é um corpo de informações organizadas e sistematizadas sobre os fatos e que, no contexto escolar atual, devem ser decoradas para a prova. Porém, as escolas também possuem elementos da modernidade, que valorizam o poder da razão, da atividade racional, para que os conhecimentos da cultura universal sejam transmitidos às gerações futuras, o que vem, em muitos casos, a desvalorizar os saberes locais.

Dessa forma, acreditamos na urgência de uma reconfiguração no nosso sistema de ensino, começando pelo próprio conceito de educação; desconstruindo a matriz teórica que alimenta a ideia de escola de qualidade como patrimônio de uma elite econômica, buscando avanços e melhorias das nossas escolas nos aspectos físicos, humanos e pedagógicos. Assim,

Temos, primeiro de tudo, de restabelecer o verdadeiro conceito de educação, retirando-lhe todo aspecto formal, herdado de um conceito de escolas para o privilégio e, por isto mesmo, reguladas apenas pela lei e por toda a sua parafernália formalística, e caracterizá-la, enfaticamente, como um processo de cultivo e amadurecimento individual, insusceptível de ser burlado, pois corresponde a um crescimento orgânico, humano, governado por normas científicas e técnicas, e não jurídicas, e a ser julgado sempre a posteriori e não pelo cumprimento formal de condições estabelecidas a priori. (Teixeira, 2007, p.100)

Nesse sentido, faz-se necessário um processo de democratização real, para além das leis e propostas que costumeiramente se perdem apenas nos documentos e discursos, mas também reflexiva, com a participação dos segmentos 
sociais organizados na busca da efetivação de uma educação popular e de qualidade e que rompa com a hierarquização dos saberes, promovendo um verdadeiro diálogo entre as formas de conhecer e saber.

Antes de explicitarmos nossa concepção de um ensino de história que possa proporcionar a democratização no processo educativo, traçaremos algumas reflexões acerca da construção do saber no Brasil e na América Latina, com base em autores da Educação Popular, a partir da coletânea organizada por Edgard Lander, A colonialidade do saber: eurocentrismo e ciências sociais - perspectivas latino-americanas, pois entendemos que essa colonialidade é um dos fatores contribuintes para a educação de formato elitista em nosso país, influenciando diretamente na nossa história e no ensino dela.

\section{A Colonialidade do saber e da História na América latina}

Somos, como país e mesmo como continente, os filhos mais recentes da história da humanidade, ao menos da história escrita, autoritária, colonizadora e eurocêntrica. Pois, se considerarmos 1492 o princípio da nossa história, estaremos obedecendo a um olhar europeu na sua busca por mercados consumidores no período das Grandes Navegações e no contexto da Contrarreforma e da sua tentativa de cristianizar o mundo para além da Europa. Essa prática, que por muito tempo foi comum nos livros de história e nas salas de aula, exclui a história e a cultura, na sua maioria oral, dos incas, maias, astecas, tupis, guaranis, macro-jês e tantos outros povos da América pré-colombiana.

As mais diversas comunidades nativas, erroneamente batizadas de "índios", foram exploradas e conquistadas pelos europeus, que impuseram suas culturas e suas verdades, demonizando os que não se alinhavam às suas imposições. Devemos considerar, porém, que a colonização não foi aceita passivamente, o que a tornou violenta; e que nossa cultura, como a vivenciamos, não é exclusividade dos conquistadores brancos, mas resultado da interação das várias formas de pensar o mundo, envolvidas nas lutas no continente, o que não caracteriza uma relação de igualdade ou de inferioridade diante da cultura europeia.

Além da situação de injustiça e desigualdades herdadas do colonialismo e dos imperialismos, o professor Carlos Walter Porto-Gonçalves, da 
Universidade Federal Fluminense, na apresentação da edição em português da obra organizada por Lander, nos alerta:

A Colonialidade do Saber nos revela, ainda, que, para além dos legados de desigualdade e injustiça social profundos do colonialismo e do imperialismo, já assinalados pela teoria da dependência e outras, há um legado epistemológico do eurocentrismo que nos impede de compreender o mundo a partir do próprio mundo em que vivemos e das epistemes que lhe são próprias. (Lander, 2005, p.3)

Nesse sentido, faz-se imprescindível questionarmos como a nossa formação escolar foi e continua sendo construída; como os conteúdos foram e são selecionados para comporem nossos currículos e livros, ou como nossas instituições escolares estão organizadas e como os manuais didáticos são escolhas feitas por outros e dificilmente pelo conjunto dos professores, e nunca em conjunto com os alunos.

Podemos verificar a influência da colonialidade europeia do saber na nossa cultura pela divisão tradicional quadripartite da História - História Antiga, História Medieval, História Moderna e História Contemporânea - que está associada a acontecimentos importantes para o continente europeu e que é incorporada a nossa prática educativa, muitas vezes, como a única aceita entre os historiadores. Estudamos sobre a importância do pensamento e da filosofia greco-romanos, exaltamos a Revolução Industrial e a Revolução Francesa como eventos essenciais para o desenvolvimento da humanidade, como se o mundo dependesse, exclusivamente, do Continente Europeu e de seus marcos históricos.

Percebemos, assim, que a história, que é nosso objeto de análise, foi-nos imposta de forma positivista, com uma visão europeizada, preocupada, principalmente, com aspectos políticos e a ação dos homens considerados heróis. A esse respeito, Fonseca esclarece que

a História do Brasil, durante muitos anos, foi tratada nos programas de ensino como pequeno apêndice da História Universal. À medida que o país se europeíza, deixa de ser "bárbaro", "atrasado" e começa a se organizar "à imagem da Europa", ele começa a "entrar na História" e consequentemente passa a ser parte mais significativa dos programas de ensino. (Fonseca, 1995, p.45) 
É só no Estado Novo que a disciplina de história do Brasil se desvincula do ensino de história universal quadripartite e se torna disciplina autônoma, mas, mesmo assim, termina por reafirmar o modelo quadripartite francês. Essa mudança está ligada a um dos interesses do governo ditatorial, que é o incentivo à nacionalização, ao patriotismo, ao civismo e ao progresso.

Seguindo essa perspectiva da colonialidade do saber, cabe-nos perguntar, principalmente enquanto professores de história, "por que a Revolução do Haiti esteve ausente dos livros de história por tanto tempo?", "na América Latina o fim do colonialismo significou o fim da colonialidade?", entre tantas outras memórias e esquecimentos da nossa história oficial.

Partindo dessas indagações, a proposta da obra de Lander é, nessa perspectiva, recuperar a simultaneidade dos diferentes lugares na conformação de nosso mundo, abrindo espaço para que várias epistemes dialoguem, pois em nossa história devemos reconhecer que há pensamentos que aprenderam a viver entre lógicas distintas. Somos mais do que multiculturais, somos interculturais, por isso entendemos ser urgente um processo de diálogo de saberes.

Além disso, Lander faz uma tentativa de busca de alternativas para a explicação das várias realidades que não sejam conformistas com a perspectiva europeia e que não naturalizem o neoliberalismo como, nos seus dizeres (Lander, 2005, p.8), "uma extraordinária síntese dos pressupostos e dos valores básicos da sociedade liberal moderna no que diz respeito ao ser humano, à riqueza, à natureza, à história, ao progresso, ao conhecimento e à boa vida".

Faz-se necessário evidenciar que uma ampla gama de buscas alternativas a essa episteme colonizadora europeia, próprias da América Latina e de seu contexto histórico, vêm sendo propostas por vários estudiosos. De acordo com o autor,

No pensamento social latino-americano, seja do interior do continente ou de fora dele e sem chegar a constituir um corpo coerente, produziu-se uma ampla gama de buscas, de formas alternativas do conhecer, questionando-se o caráter colonial/eurocêntrico dos saberes sociais sobre o continente, o regime de separações que lhes servem de fundamento, e a ideia mesma da modernidade como modelo civilizatório universal. (Lander, 2005, p.15) 
Como campo contrário a esse modelo de educação e em busca de alternativas, nas últimas décadas os movimentos de Educação Popular e de criação de uma forma própria de entender e de agir na realidade têm ganhado visibilidade na América Latina a partir das concepções da teologia da libertação, da filosofia da libertação e da Pedagogia da libertação, com base em autores como Dussel, Paulo Freire, Orlando Fals Borda e muitos outros que se apoiam na concepção da Educação Popular e que têm, segundo Maritza Montero, citada em Lander (2005, p.15), as seguintes características:

- Uma concepção de comunidade e de participação, contrariando a ideia de individualidade e competitividade associada ao neoliberalismo, assim como do saber popular, como formas de constituição e ao mesmo tempo produto de uma episteme de relação. Assim, precisamos refletir sobre como formar o professor/educador de História para dar conta dessa demanda do cotidiano (dos fazeres e viveres) em relação com o conhecimento histórico, que também é fruto de outros fazeres e viveres em outras escalas temporárias.

- A ideia de libertação através da práxis, que pressupõe a mobilização da consciência, e um sentido crítico que conduz à desnaturalização das formas canônicas de aprender-construir-ser no mundo. Acerca dessa afirmação, questionamo-nos: como construir uma dialética entre esses dois universos, o da teoria e o da prática, onde estes se separam e se juntam? E que possibilidades temos para buscar essa síntese prática e teórica no contexto da formação do professor?

- A redefinição do papel do pesquisador social, o reconhecimento do Outro como Si Mesmo e, portanto, a do sujeito-objeto da investigação como ator social e construtor do conhecimento. Precisamos discutir e propor ações de como perceber a instituição escolar como local de saber situado num tempo e espaço, germinando conhecimentos e saberes que deveriam ser agregados ao sistema educacional como um todo.

- O caráter histórico, indeterminado, indefinido, inacabado e relativo do conhecimento. A multiplicidade de vozes, de mundos de vida, a pluralidade epistêmica. Uma questão complexa que sugere outro desafio prático-reflexivo: como as diversidades e leituras do processo histórico poderiam assumir uma dimensão histórica e pedagógica na formação 
do professor, como elementos a somarem aos conhecimentos sistematizados e resumidos dos manuais didáticos?

- A perspectiva da dependência, e logo, a da resistência. A tensão entre minorias e maiorias e os modos alternativos de fazer-conhecer.

- A revisão de métodos, as contribuições e as transformações provocadas por eles.

Essas características são inerentes à Educação Popular, que vem se apresentando como uma concepção contra-hegemônica e antielitista e tem buscado um diálogo com as várias formas de saber, inclusive com a concepção eurocêntrica colonizadora. Portanto, nossa intenção na sequência do texto é apresentar as discussões que vêm sendo realizadas no campo da Educação Popular, na sua tentativa de empreender uma episteme própria da América Latina, além de buscar uma aproximação desse diálogo com a história e com o ensino de história e as possibilidades de democratização dessa área do saber no Brasil.

\section{EdUCAÇÃo Popular E HistóRIA LOCAL: POSSIBILIDAdES} DE UM ENSINO DE HisTóRIA DEMOCRÁTICO

Delineamos, a partir deste momento, uma tentativa de aproximação dos ideais da Educação Popular com a perspectiva de um ensino de história que rompa com a colonialidade histórica presente em nossas salas de aula, que valorize os contextos locais, que visibilize as vivências e as culturas populares a partir do olhar dos alunos, sem que para isso se realize uma fragmentação das realidades. Entendemos, assim, que essa proposta é uma tentativa válida de diálogo entre o texto e o contexto, entre a história global e as várias histórias locais.

Assim como a proposta da história local, que busca valorizar o contexto das vivências populares, suas culturas e suas lutas, a Educação Popular se apresenta como uma concepção de educação que tende a problematizar as relações sociais e democratizar as historicidades dos oprimidos. Nos dizeres de Torres e Gadotti a Educação Popular

É um paradigma teórico que surge no calor das lutas populares. Trata de codificar e decodificar os temas geradores dessas lutas, busca colaborar com os movimen- 
tos sociais e os partidos políticos que expressam essas lutas. Trata de diminuir o impacto da crise social na pobreza e de dar voz à indignação e ao desespero moral do pobre, do oprimido, do indígena, do camponês, da mulher, do afro-americano, do analfabeto e do trabalhador industrial. (Torres; Gadotti, 1994, p.8)

Para esse paradigma, que é político, mas que também é didático, a história é de essencial importância para contextualizar as lutas e, consequentemente, colaborar com os mais diversos grupos sociais na valorização do sentimento de pertencimento e na construção de suas identidades sociais. Freire (2002) alerta para a importância da conscientização no processo educativo, para que este não seja um fenômeno historicamente autônomo, mas sim vinculado às realidades, sempre.

Para esse autor, deve-se relacionar o texto com o contexto, e a escola deve aproximar o que se ensina com o que se vive. A leitura da palavra não deve ser uma prática distante da leitura do mundo (Freire, 2002). Freire valoriza a história e a historicidade como uma área essencial para uma educação libertadora e dialógica, para ele a importância do ato de ler é a importância de ler e compreender o mundo, de ler e entender a sua própria história. $\mathrm{O}$ autor nos aponta que:

Um excelente trabalho, numa área popular, sobretudo camponesa, que poderia ser desenvolvido por bibliotecárias, documentalistas, educadoras, historiadoras seria, por exemplo, o do levantamento da história da área através de entrevistas gravadas, em que as mais velhas e os mais velhos habitantes da área, como testemunhos presentes, fossem fixando os momentos fundamentais da sua história comum. Dentro de algum tempo se teria um acervo de estórias que, no fundo, fariam parte viva da História da área. (Freire, 2002, p.33)

Percebemos uma ligação da história local com a visão freireana de educação, pois, nos dois casos, a vivência dos alunos é de suma importância no aprendizado dos educandos, ressignificando o aprendizado. Nessa direção, a educação a partir da realidade torna-se importante e consequentemente mais acessível, porém, deve ser conectada com a realidade global, pois só assim será essencial na busca da construção das identidades dos sujeitos do processo educativo.

A citação de Freire é reveladora e nos aponta para um caminho essencial: a aproximação da Educação Popular à história local. Mas o que podemos 
entender como história local, e como ela pode se relacionar com a Educação Popular? A partir de tais questões, perseguimos uma sistematização que relacione esses dois campos de saber que estão muito próximos na prática, mas que têm sido teorizados separadamente.

É comum existir uma ideia do local, segundo afirma Samuel (1990, p.227), como "uma entidade distinta e separada, que pode ser estudada como um conjunto cultural". Acreditamos, porém, que independentemente do recorte que o historiador escolha, a história local só será consistente se for trabalhada sem perder de vista as relações com as demais escalas históricas. Comungamos da visão de Gasparello (1996, p.89) quando afirma que a história local é "um princípio metodológico, que encontra sua validade ao atender aos pressupostos da construção de um conhecimento que interage com um saber que se torna significativo e consciente, constituindo-se em sua relevância social”.

Dessa forma, a história local se apresenta como recorte teórico-metodológico que busca evidenciar a ação dos grupos excluídos socialmente, como os negros, analfabetos, pobres, índios, homossexuais e trabalhadores, tudo isso dentro da sua localidade, sem deixar de relacioná-la com a dimensão global da história e sem deixar de problematizá-la. Além disso, como afirma Barbosa (2005, p.27), "através do recurso à história local podem-se formular perguntas, suscitar questões, estabelecer a relação entre prática e teoria”, um diálogo essencial segundo a Educação Popular.

Entendemos ser primordial estudar a localidade, sem perder de vista sua relação com um processo/contexto maior. É possível uma aproximação temporal e espacial entre realidades distintas, aproximar determinada época/fato/ processo com a realidade mais imediata, pois, podemos descobrir como as pessoas se relacionavam, como viviam em grupo, e estabelecer relações com o presente. Essa afirmação significa, como afirma Samuel (1990, p.229), “escolher como ponto de partida algum elemento da vida que seja, por si só, limitado tanto em tempo como em espaço, mas usado como uma janela para o mundo".

Também não existe na história local uma pretensão de desconstrução da ideia do nacional, ou o entendimento de que os recortes formam entidades autônomas, mas uma percepção diferenciada quanto à participação da escala local no contexto mais global. Segundo Manique e Proença, "Sob o ponto de vista científico, a história local e regional evita o erro grosseiro de se considerar 
o nacional como um todo homogêneo, o que, em termos de investigação científica, produz uma percepção desfocada e distorcida da dinâmica das sociedades" (Manique; Proença, 1994, p.25).

A história local proporciona, mediante análises de espaços com recortes menores, novas possibilidades de redimensionar e de repensar a própria história nacional. Pois entendemos que a primeira, por sua natureza, tende a tratar das diferenças e multiplicidades, ao passo que a segunda focaliza as semelhanças dos fenômenos sociais. Assim, de acordo com Amado (1990), a importância do estudo local pode "oferecer novas óticas de análise no estudo de cunho nacional, podendo apontar todas as questões fundamentais da história (como os movimentos sociais, a ação do Estado, as atividades econômicas, a identidade cultural etc.) a partir de um ângulo de visão que faz aflorar o específico, o próprio, o particular" (Amado, 1990, p.12-13).

Tanto a Educação Popular quando história local, nesse sentido, têm intenções de contribuição na construção coletiva de saberes significativos no processo educativo, o que, metodologicamente, pode acontecer com a participação dos segmentos sociais populares, que representam uma grande maioria excluída do conjunto das etapas e realizações de um projeto educativo.

A Educação Popular, enquanto paradigma educacional, mesmo com muitas resistências, tem alcançado seu espaço no meio acadêmico, e nos fazeres educacionais de muitos movimentos sociais já é uma prática aceita e difundida, mesmo porque é nesse meio que ela surge. Quanto à história local, é uma prática que precisa ser mais encorajada e concretizada na Educação Básica, pois ainda está muito restrita a grupos circunscritos de pesquisadores e de projetos acadêmicos. Barbosa destaca que

a história local, como recurso teórico metodológico de abordagem para a pesquisa e para o ensino de história, apesar do crescente interesse em sua aplicação, seja na pesquisa propriamente dita, seja na sua aplicação em sala de aula, tem, no Brasil, ficado circunscrita para além de trabalhos monográficos, dissertações e teses, às iniciativas e experiências localizadas, especialmente entre grupos de pesquisadores que têm se debruçado sobre a temática, produzindo materiais didáticos ou criando coletivamente projetos de pesquisa específicos e grupos de estudos. (Barbosa, 2005, p.35-36) 
Diante do exposto, as ideias que se seguem têm por finalidade contribuir para a associação entre a concepção de Educação Popular e o recurso metodológico da história local, compreendendo estar colaborando para o processo de construção de uma educação mais justa e democrática, que leve em conta as mais diversas realidades sociais possíveis. Para isso, partimos dos pontos que Torres e Gadotti (1994) chamam de intuições originais da educação popular e que nos convidam a ser otimistas e refletem uma recusa da educação do colonizador: 1) A ênfase nas condições gnosiológicas da prática educativa; 2) A educação como produção e não meramente como transmissão do conhecimento; 3) A luta por uma educação emancipadora, que suspeita do arbitrário cultural, o qual, necessariamente, esconde um momento de dominação; 4) A defesa de uma educação para a liberdade, preconização da vida democrática; 5) A recusa do autoritarismo, da manipulação, da ideologização que surge também ao estabelecer hierarquias rígidas entre o professor que sabe (e por isso ensina) e o aluno que tem de aprender (e por isso estuda).

\section{A ÊNFASE NAS CONDIÇÕES GNOSIOLÓGICAS DA PRÁTICA EDUCATIVA}

A Educação Popular, entre outras preocupações, se ocupa e reflete acerca do conhecimento, da sua natureza, do seu valor e de seus limites, caracterizando uma prática gnosiológica, pois não se restringe ao estudo sistemático do conhecimento científico, mas compreende que o conhecimento é vivenciado e construído nos mais diversos espaços sociais.

Nesse sentido, a prática educativa não se realiza apenas na escola, ela é intrínseca às vivências sociais, acontece na família, na igreja, no trabalho, nos movimentos sociais e sindicatos, nas praças, de forma harmoniosa e conflituosa. Para a Educação Popular, o ato de conhecer não se restringe à transmissão de um saber, este tem de ser questionado, problematizado e refletido acerca de seus valores, de suas naturezas, de suas intenções, e acontece nas relações entre educador e educandos, mediatizados pelo mundo. De acordo com Freire,

a educação libertadora, problematizadora, já não pode ser o ato de depositar, ou de narrar, ou de transferir, ou de transmitir "conhecimentos" e valores aos educandos, meros pacientes, à maneira da educação "bancária", mas um ato cognoscente. Como atuação gnosiológica, em que o objeto cognoscível, em lugar de ser o término 
do ato cognoscente de um sujeito, é o mediatizador de sujeitos cognoscentes, educador, de um lado, educandos, de outro, a educação problematizadora coloca, desde logo, a exigência da superação da contradição educador-educandos. Sem esta, não é possível a relação dialógica, indispensável à cognoscibilidade dos sujeitos cognoscentes, em torno do mesmo objeto cognoscível. (Freire, 1987, p.39)

A Educação Popular é, por sua natureza, uma prática filosófica de educação, que não aceita o outro como receptáculo do conhecimento, mas compreende a prática educativa como um ato dialógico, questionador e político e que tanto pode libertar como oprimir, dependendo do seu direcionamento. Por isso, é necessário não só aprender, mas compreender a razão de ser do que se aprende.

Partindo dessa perspectiva, a proposta de história local rompe com a concepção de história nacional, pronta e acabada, um conhecimento inquestionável que é depositado nos educandos, aproximando-a da Educação Popular, possibilitando um diálogo da história oficial com as histórias mais próximas dos alunos. Assim, a história, que é objeto cognoscível, passa a mediatizar a construção do conhecimento entre educador e educando, pois deixa de ser abstrata e distante para ser concreta e próxima, e não mais um fim em si mesmo. Nos dizeres de Barbosa, "Em princípio, temos que, se o sujeito adquire ou tem o conhecimento histórico, isso propiciará a consciência da sua identidade social, levando-o a ação. Seria a interação entre o conhecimento e a ação - conhecimento para a ação. O local é, pois, o espaço de atuação dos sujeitos históricos. Na realidade, o que significa o fazer da própria história" (Barbosa, 2005, p.38).

Ancorados nessa visão, nossa compreensão é de que, assim como a Educação Popular, é importante que a história enquanto conhecimento seja pensada e construída no conjunto das experiências dos sujeitos sociais, e não imposta sob uma perspectiva elitista. Essa proposição se apresenta como uma ligação para o ponto a seguir.

\section{A EDUCAÇÃo COMO PRODUÇÃo E NÃO MERAMENTE COMO TRANSMISSÃO DO CONHECIMENTO}

A realidade do nosso sistema educativo escolar ainda apresenta práticas pedagógicas configuradas exclusivamente pelo viés narrativo e dissertativo, o 
que se acentua ainda mais com relação às disciplinas ditas teóricas, como é o caso de História e Geografia. Uma concepção que Freire (1987) chama de "educação bancária". Segundo o autor, é um caso de "Narração de conteúdos que, por isto mesmo, tendem a petrificar-se ou a fazer-se algo quase morto, sejam valores ou dimensões concretas da realidade. Narração ou dissertação que implica um sujeito - o narrador - e objetos pacientes, ouvintes - os educandos" (Freire, 1987, p.33).

Por meio da narração são "depositadas" histórias de heróis e seus feitos imprescindíveis, e, segundo a concepção bancária de educação, cabe aos educandos decorar os fatos, memorizar os feitos e reproduzi-los quando solicitado pelo professor. Fatos históricos que não têm significado para os educandos e que, pelo contrário, inferiorizam seus feitos e os consagram como incapazes ou preguiçosos. Em muitos contextos, a educação formal tem imposto uma história que os educandos devem receber pacientemente, memorizar e repetir. Ainda segundo esse autor, "Na visão 'bancária' da educação, o 'saber' é uma doação dos que se julgam sábios aos que julgam nada saber. Doação que se funda numa das manifestações instrumentais da ideologia da opressão - a absolutização da ignorância, que constitui o que chamamos de alienação da ignorância, segundo a qual esta se encontra sempre no outro" (Freire, 1987, p.33).

No terreno da Educação Popular, pensá-la como forma de doação de saberes é uma concepção da qual buscamos nos afastar, pelo contrário, acreditamos na numerosa, diversa e criativa produção de uma maioria, ainda excluída dos processos formais de ensino, mas que cria cotidianamente estratégias de inteligências que são inerentes às suas vivências, marcadas por um amplo campo de significados sociais. Nesse sentido, a Educação Popular tem como proposta a construção conjunta de conhecimentos e a valorização das diversas culturas.

O recorte de história local, que se coaduna com a Educação Popular, nessa perspectiva, pode contribuir com a superação da "educação bancária", pois o espaço local passa a se constituir como ponto de referência, onde são consideradas ações individuais e coletivas, que dialogam constantemente, com outras histórias. Dessa forma, entendemos e defendemos que tanto a Educação Popular quanto a história local são concepções educativas que incentivam o fazer, a participação e a construção do conhecimento, colocando no centro de suas análises os sujeitos e suas lutas sociais, que deixam de ser receptores passivos 
e assumem posturas educativas, como detentores de saberes e agentes reflexivos de suas histórias.

\section{A LUTA POR UMA EDUCAÇÃO EMANCIPADORA, QUE SUSPEITA DO ARBITRÁRIO CULTURAL, O QUAL, NECESSARIAMENTE, ESCONDE UM MOMENTO DE DOMINAÇÃO}

A prática educativa formal, comum nos espaços escolares oficiais, estabeleceu-se historicamente por um sectarismo e por um caráter conformador das situações vividas pelos setores mais empobrecidos do nosso país. Nessa perspectiva, trava uma luta constante na tentativa de formar cidadãos convictos de seus deveres sociais, com uma identidade que lhes é imposta por meio de ideologias e símbolos nacionais que foram forjados por uma colonialidade eurocêntrica e que objetivam a transformação de homens, mulheres, crianças e idosos em sujeitos sem consciência crítica.

Nesse sentido, o ensino de história, enquanto campo de saber oficial, a princípio pode parecer ingênuo e desinteressado, mas o conhecimento da história pode e tem sido utilizado, na maioria das vezes, como uma forma de controle e de dominação social. Manter a ordem já estabelecida é um dos objetivos do Estado nas sociedades estruturadas em classes sociais antagônicas. Para isso, o conhecimento da história se apresenta como uma das formas de controle sobre as classes dominadas. Segundo Chesneaux (1995),

Nas sociedades de classe, a história faz parte dos instrumentos por meio dos quais a classe dirigente mantém seu poder. $\mathrm{O}$ aparelho de Estado procura controlar o passado, simultaneamente, no nível da política prática e no nível da ideologia. (p.28)

As classes dirigentes e o poder do Estado frequentemente apelam ao passado de modo explícito: a tradição, aí incluídos os seus componentes culturais específicos, a continuidade e a história são invocadas como fundamentos do princípio de sua dominação. (p.29)

Uma ação dessa natureza teórica e prática consiste no que Fontana (1998) chama de "legitimar a ordem estabelecida". Ele afirma que, desde o surgimento da História, sua principal, porém não única função social é a de manter o 
controle da situação. Para isso, ela se utiliza de vários meios, como a genealogia, os poemas, as fórmulas rituais, os provérbios. Ainda segundo esse autor, "Desde os começos, nas manifestações mais primárias e elementares, a História tem tido sempre uma função social - geralmente a de legitimar a ordem estabelecida -, ainda que tenha tendido a mascará-la, apresentando-se com a aparência de uma narração objetiva de acontecimentos concretos" (Fontana, 1998, p.15).

Muitas vezes temos vivenciado um ensino de história e uma educação que impõem um arbitrário cultural, uma razão ou norma moral de validade universal, que conforma uma cultura como inferior e ignorante e exalta um saber intelectual, imposto como superior, verdadeiro e absoluto. Assim como a história trabalha com fatos, ela atua na manutenção daquilo que pretende que seja lembrado, ou do que se pretende que seja esquecido. Em outras palavras, a história se utiliza ativamente da memória coletiva. Lembrar os heróis nacionais, esquecer os movimentos populares organizados, durante muito tempo, tem sido a lógica da história a serviço do Estado em vários momentos históricos.

Porém, essa imposição sempre encontrou, e ainda hoje encontra resistências e forças que buscam a liberdade e a conscientização do seu estado de explorados para, a partir de então, lutar contra essa situação de exploração. Segundo Freire (1987, p.12) é "a conscientização, que lhe possibilita inserir-se no processo histórico, como sujeito, evita os fanatismos e o inscreve na busca de sua afirmação". Podemos destacar a partir dessa ideia que o professor de história deveria ser formado para atuar nessa direção, perceber-se na história e fazer os alunos se perceberem também, ambos como sujeitos históricos participativos.

Registramos que, ao longo da História, movimentos contra essa imposição educacional têm surgido. Alguns são silenciados e esquecidos, mas outros se impõem e mantêm-se como perspectiva emancipadora de educação. Nessa perspectiva, a Educação Popular se caracteriza como uma concepção educacional que busca romper com a dominação política, social e cultural por valorizar a participação das classes e grupos populares na construção constante da história. Uma perspectiva pedagógica que revele aos educandos que eles “pouco sabem de si, de seu 'posto no cosmos', e se inquietam por saber mais. Estará, aliás no reconhecimento do seu pouco saber de si uma das razões desta procura. Ao instalar-se na quase, senão trágica descoberta do seu pouco saber de 
si, se fazem problemas a eles mesmos. Indagam. Respondem, e suas respostas os levam a novas perguntas" (Freire, 1987, p.16).

Compreendemos assim a Educação Popular como um fazer pedagógico pautado na pergunta, na problematização constante e no sentido de inconclusão da história e no permanente movimento de busca, de libertação. E cada libertação, cabe destacar, resulta de uma síntese, de uma ação concreta. Assim, enquanto práticas pedagógicas, a história local e a Educação Popular têm como ponto de referência o local, de onde partem as ações práticas dos indivíduos e da coletividade. A esse respeito, Alain Bourdin esclarece que

é na escala local, na do bairro, da cidade ou da microrregião que alguns problemas da vida diária podem ser regulados, por exemplo, os que se referem à organização dos serviços públicos. A solidariedade e a sociabilidade podem se desenvolver dentro de redes muito dispersas, mas são muitas vezes mais fáceis de criar quando se apoiam na vizinhança. Enfim, o quadro local pode servir para se organizarem grupos muito unidos, ou coalizões para a ação. (Bourdin, 2001, p.13)

Nesse sentido, a dominação, mesmo que tenha sua origem na nossa colonização, pode ser superada pelo conhecimento e reconhecimento de si mesmo enquanto sujeito histórico e pela importância de seus fazeres políticos e culturais, fatores transformadores da realidade social.

\section{A DEFESA DE UMA EDUCAÇÃo PARA A LIBERDADE, PRECONIZAÇÃO DA VIDA DEMOCRÁTICA}

A partir do reconhecimento de si mesmo enquanto sujeito histórico, a busca dos segmentos empobrecidos e oprimidos é de libertação dessa condição, de romper com a exploração e preconizar a vida democrática para todos. Essa práxis se materializa em uma pedagogia que "Tem que ser forjada com ele e não para ele, enquanto homens ou povos, na luta incessante de recuperação da sua humanidade. Pedagogia que faça da opressão e de suas causas objeto da reflexão dos oprimidos, de que resultará o seu engajamento necessário na luta por sua libertação, em que esta pedagogia se fará e refará" (Freire, 1987, p.17).

Partindo dessa concepção de educação, concebemos a história local como recorte metodológico capaz de propiciar uma reflexão acerca da condição de 
oprimido de cada sujeito por meio da articulação entre conhecimento e identidade social dos seus agentes, o que favorece a constituição do sentimento de pertencimento e de superação da condição de opressão, sem que para isso o indivíduo se torne opressor. Nesse sentido, compreendemos a identidade social como um elemento que pode proporcionar um equilíbrio importante na superação da condição do educando como elemento alienado e que

implica a consciência que se tem de si mesmo. Essa consciência supõe um reconhecimento do mundo (contexto) no qual se existe e atua. Portanto, por identidade social pode-se entender o reconhecimento de si próprio como sujeito da história (processo). E, na medida em que o sujeito da história é realizador de ações, ele é também objeto da história (ciência). A identidade social é, portanto, um atributo de sujeitos da história que se definem e se reconhecem na ação. (Neves, 1997, p.15)

Nesse olhar, a liberdade implica a superação da condição de oprimido, que não pode ser individualista, nem tampouco pode gerar outro opressor, mas contribuir na libertação democrática, do grupo social ao qual o indivíduo pertence. É por isso que a Educação Popular está pautada na coletividade, mesmo que não descarte os fenômenos individuais. Ela pressupõe a luta dos vários grupos sociais, que ao se reconhecerem como tais encontram o motor na busca pela libertação.

A identidade social, compreendida pela história local, não suprime a condição de indivíduo como ser único, contraditório e conflituoso dentro das lutas e ideias das quais o grupo a que pertence defende, mas ela considera os pontos que unem os sujeitos ao grupo como um todo, na configuração de sua identidade social, propiciando a intervenção histórica de forma consciente e comprometida. Por isso, compreendemos que "Na perspectiva da história local, essa composição da identidade social calcada numa práxis histórica, considerando que a ligação entre conhecimento e ação nos espaços de vivência do sujeito - que é sempre local - é imprescindível à condução de intervenções no processo histórico de forma mais consciente e comprometida" (Barbosa, 2005, p.39-40).

É uma visão de história que concebe que o fortalecimento necessário para a superação da condição de oprimido reside na percepção de si mesmo, mas que a liberdade só será possível a partir da preconização da vida democrática, 
que acontece com a participação de todos e a superação das contradições e dos conflitos internos.

\section{A RECUSA DO AUTORITARISMO, DA MANIPULAÇÃO, DA IDEOLOGIZAÇÃO QUE SURGEM TAMBÉM AO ESTABELECER HIERARQUIAS RÍGIDAS ENTRE O PROFESSOR QUE SABE (E POR ISSO ENSINA) E O ALUNO QUE TEM DE APRENDER (E POR ISSO ESTUDA)}

Essa concepção da Educação Popular está mais próxima da prática pedagógica escolar, mas não descarta o processo de ensino e aprendizagem em outras instituições, quer sejam movimentos sociais, sindicatos, cooperativas, enfim, é uma perspectiva metodológica que busca romper com a hierarquia da educação bancária, centrada na figura do professor como detentor do único conhecimento possível e que percebe o aluno como uma "tábua rasa", pronta para ser preenchida com informações.

A partir desse entendimento, a Educação Popular se constitui em uma perspectiva que busca romper com o autoritarismo hierárquico entre professor e aluno, contrariando a educação bancária, respeitando o saber do educando e levando em conta suas vivências locais, suas culturas e suas realidades sociais, numa perspectiva política e questionadora.

Por isso mesmo, pensar certo coloca ao professor ou, mais amplamente, à escola, o dever de não só respeitar os saberes com que os educandos, sobretudo os das classes populares, chegam a ela - saberes socialmente construídos na prática comunitária - mas também, como há mais de 30 anos venho sugerindo, discutir com os alunos a razão de ser de alguns desses saberes em relação com o ensino dos conteúdos. Por que não aproveitar a experiência que têm os alunos de viver em áreas da cidade descuidadas pelo poder público para discutir, por exemplo, a poluição dos riachos e dos córregos e os baixos níveis de bem-estar das populações, os lixões e os riscos que oferecem à saúde das gentes? Por que não há lixões no coração dos bairros ricos e mesmo puramente remediados dos centros urbanos? (Freire, 1996, p.16)

Tomando como referência o exposto, compreendemos que a história local e a Educação Popular estão intimamente próximas em suas naturezas, no que diz respeito a suas concepções de educação. Como não aproximar essas 
concepções que têm como foco o diálogo da disciplina cujo conteúdo é trabalhado em sala de aula com as questões sociais vivenciadas pelos educandos? Uma perspectiva na qual os conteúdos terão novos sentidos e significados, responderão às angústias e anseios dos alunos e poderão colaborar na formação de cidadãos realmente críticos, sujeitos para além da conformação imposta pelas classes dominantes.

Por que não discutir com os alunos a realidade concreta a que se deva associar a disciplina cujo conteúdo se ensina, a realidade agressiva em que a violência é a constante e a convivência das pessoas é muito maior com a morte do que com a vida? Por que não estabelecer uma necessária "intimidade" entre os saberes curriculares fundamentais aos alunos e a experiência social que eles têm como indivíduos? Por que não discutir as implicações políticas e ideológicas de um tal descaso dos dominantes pelas áreas pobres da cidade? A ética de classe embutida neste descaso? (Freire, 1996, p.17)

Educação Popular e história local complementam-se à medida que realizam o diálogo entre saber escolar e o saber social dos educandos, dos professores, dos pais e das comunidades circunvizinhas. De um lado, a Educação Popular propõe uma educação renovadora e crítica, que busca a formação de um cidadão completo, por meio da leitura da palavra e do mundo. Por outro, a história local propõe um ensino de História diferenciado, que parta do concreto para o abstrato; que possibilite a incorporação das experiências da vida dos alunos que se dão num lócus específico; que permita a inserção do aluno na realidade do passado local; que promova o contato do aluno com as instituições locais e seus modos de funcionamento, além de possibilitar o acesso às fontes locais (museus, arquivos, bibliotecas, monumentos, paisagens etc.).

\section{CONSIDERAÇÕES FINAIS}

Cientes das contribuições e provocações apontadas no corpo deste artigo, finalizamos certos da necessidade do amadurecimento dessas e novas reflexões que emergiram. Consideramos que algumas afirmações constantes no desenrolar do trabalho são passíveis de análise e de contestações, o que não invalida as ideias defendidas no texto, mesmo que, algumas vezes, com o ar de 
militância ideológica, mas com muito sabor de quem exerce e pesquisa a profissão de professor de história.

Nesse contexto de incertezas, porém de muitos desafios e conquistas, consideramos inconteste a colonização do saber e sua influência sobre a educação formal e sobre o ensino de História. Compreendemos e reiteramos que nosso sistema educacional ainda circula o ranço dos fundamentos de uma perspectiva pedagógica bancária. Nesse sentido, não conseguimos construir uma metodologia de ensino e trabalho escolar que repense as estruturas institucionais locais e nacionais, isso seria um grande avanço na construção de um novo pensar e fazer histórico. Um retrato dessa situação é a forte ausência da história local/dos municípios numa visão de Educação Popular.

Constatamos, porém, que o ideal de conformação e alinhamento pretendido pelo Estado enfrenta manifestações contrárias e que, ao longo da história, concepções contra-hegemônicas de educação surgiram e ainda hoje travam batalhas ideológicas e práticas para conquistar um espaço mais efetivo na sociedade, no sentido de construir uma educação mais comprometida com as identidades sociais locais, sobretudo dos esquecidos da história oficial.

Por meio das reflexões aqui empreendidas, ratificamos a Educação Popular como um paradigma educacional problematizante, que busca constantemente um processo de ensino contextualizado, politizado e que dialoga com vários saberes, valorizando as vivências sociais e as várias culturas dos educandos, sem portanto cair numa visão populista e localista.

Entendemos ainda que a Educação Popular pode relacionar-se com a concepção metodológica da história local, pois ambas focam na história vivida pelos educandos, rompendo com a exclusividade da historiografia oficial, europeizante e elitista. A história local e a Educação Popular estão, assim, intimamente próximas em suas epistemologias, seja nas concepções de educação, seja nas práticas educativas e por fim, no rompimento das tradições pedagógicas e escolares.

Esperamos que as reflexões tecidas até o momento sirvam de base teórica para a concretização da pesquisa de doutorado que estamos empreendendo na escola pública onde atuamos como professor de história. O que vivenciamos até o momento é o protagonismo por parte dos alunos, que têm respondido e participado ativamente do processo de investigação de suas realidades, contrariando até mesmo a ideia da escola pública como espaço de impossibilidades. 
Reiteramos a importância da construção do $e$-book de história local, que vem sendo trabalhado pelos educandos da Escola Estadual Papa Paulo VI, localizada na cidade de João Pessoa (PB), o que enxergamos como uma prática pedagógica que vai além da transmissão dos conteúdos, pois contrapõe ideias e fazeres e proporciona um ensino de história diferente da concepção bancária. Por fim, esperamos em um próximo momento apresentar e discutir os resultados dessa pesquisa que vem sendo construída em conjunto com os sujeitos pesquisados.

\section{REFERÊNCIAS}

AMADO, Janaína. História e região: reconhecendo e reconstruindo espaços. In: SILVA, Marcos (Coord.) República em migalhas: história regional e local. São Paulo: Anpuh; Marco Zero, 1990. p.7-15.

BARBOSA, Vilma de Lurdes. Contribuições para pensar, fazer e ensinar história local. Tese (Doutorado em Educação) - Universidade Federal do Rio Grande do Norte (UFRN). Natal, 2005.

BOURDIN, Alain. A questão local. Rio de Janeiro: DP\&A, 2001.

CHESNEAUX, Jean. Devemos fazer tábula rasa do passado? Sobre a história e os historiadores. São Paulo: Ática, 1995.

FERNANDES, José Ricardo Oriá. Um lugar na escola para a história local. Ensino em Re-vista, v.4, n.1, p.43-51, jan.-dez. 1995.

FONSECA, Selva Guimarães. Caminhos da história ensinada. 3.ed. Campinas, SP: Papirus, 1995.

FONTANA, Josep. História: análise do passado e projeto social. Bauru, SP: Edusc, 1998.

FREIRE, Paulo. A importância do ato de ler: em três artigos que se completam. 43.ed. São Paulo: Cortez, 2002. . Pedagogia do oprimido. Rio de Janeiro: Paz e Terra, 1987.

GASPARELLO, Arlette Medeiros. Construindo um currículo de História. In: NIKITIUK, Sonia (Org.) Repensando o ensino de História. São Paulo: Cortez, 1996. p.83-95.

LANDER, Edgardo (Org.) A colonialidade do saber: eurocentrismo e ciências sociais. Perspectivas latino-americanas. Buenos Aires: Clacso, 2005.

MANIQUE, Pedro Antônio; PROENÇA, Maria Cândida. Didática da História: patrimônio e história local. Lisboa: Texto, 1994. 
NEVES, Joana. História local e construção da identidade social. Saeculum - Revista de História, João Pessoa: Ed. Universitária; UFPB, n.3, p.13-27, jan.-dez. 1997.

SAMUEL, Raphael. História local e história oral. Revista Brasileira de História, São Paulo: Anpuh; Marco Zero, v.9, n.19, p.219-243, set. 1989-fev. 1990.

TEIXEIRA, Anísio. Educação não é privilégio. 7.ed. Rio de Janeiro: Ed. UFRJ, 2007.

TORRES, Carlos Alberto; GADOTTI, Moacir. Poder e desejo: a educação popular como modelo teórico e como prática social. In: TORRES, Carlos Alberto; GADOTTI, Moacir (Org.) Educação Popular: utopia latino-americana. São Paulo: Cortez; Edusp, 1994.

Artigo recebido em 15 de outubro de 2015. Aceito em 5 de maio de 2016. 